OPEN ACCESS

Edited by:

Jianhua $L i$,

Shandong University, China

Reviewed by:

Qihui Zhou,

Qingdao University, China

Xiumei Mo,

Donghua University, China

${ }^{*}$ Correspondence: Jiajia Xue

jiajiaxue@mail.buct.edu.cn Feng Rao

frao@pku.edu.cn

tThese authors have contributed equally to this work

Specialty section:

This article was submitted to

Nanoscience,

a section of the journal

Frontiers in Chemistry

Received: 19 December 2021 Accepted: 30 December 2021 Published: 24 January 2022

Citation:

Hao R, Cui Z, Zhang X, Tian M, Zhang L, Rao F and Xue J (2022) Rational Design and Preparation of

Functional Hydrogels for Skin

Wound Healing.

Front. Chem. 9:839055.

doi: 10.3389/fchem.2021.839055

\section{Rational Design and Preparation of Functional Hydrogels for Skin Wound Healing}

\author{
Ruinan Hao ${ }^{1 \dagger}$, Zhuoyi Cui ${ }^{1+}$, Xindan Zhang ${ }^{1}$, Ming Tian $^{2}$, Liqun Zhang ${ }^{1,2}$, Feng Rao ${ }^{3,4 \star}$ and \\ Jiajia Xue ${ }^{1,2 *}$ \\ ${ }^{1}$ Beijing Laboratory of Biomedical Materials, Beijing University of Chemical Technology, Beijing, China, ${ }^{2}$ State Key Laboratory of \\ Organic-Inorganic Composites, Beijing University of Chemical Technology, Beijing, China, ${ }^{3}$ Trauma Center, Peking University \\ People's Hospital, Beijing, China, ${ }^{4}$ Key Laboratory of Trauma and Neural Regeneration, Ministry of Education, National Trauma \\ Medical Center, Peking University, Beijing, China
}

Skin wound healing often contains a series of dynamic and complex physiological healing processes. It is a great clinical challenge to effectively treat the cutaneous wound and regenerate the damaged skin. Hydrogels have shown great promise for skin wound healing through the rational design and preparation to endow with specific functionalities. In the mini review, we firstly introduce the design and construction of various types of hydrogels based on their bonding chemistry during cross-linking. Then, we summarize the recent research progress on the functionalization of bioactive hydrogel dressings for skin wound healing, including anti-bacteria, anti-inflammatory, tissue proliferation and remodeling. In addition, we highlight the design strategies of responsive hydrogels to external physical stimuli. Ultimately, we provide perspectives on future directions and challenges of functional hydrogels for skin wound healing.

Keywords: skin wound healing, hydrogel, wound dressing, bioactive materials, tissue regeneration

\section{INTRODUCTION}

As the largest organ of the human body, skin is the most important natural barrier to protect human from external injuries (Gao et al., 2019). Due to various types of internal and external factors, such as mechanical injuries, burns, chronic skin trauma caused by diabetes and malignant tumors, human skin is extremely vulnerable to damage. At present, it is still a great clinical challenge to effectively treat the cutaneous wound and regenerate the damaged skin. Cutaneous wound healing is a dynamic and complex physiological process, which generally includes four overlapping but different periods: hemostasis, inflammation, proliferation, and remodeling (Chen et al., 2021). These four healing stages involve interactions among various types of cells and their products, bioactive factors, and extracellular matrices (ECMs) (Xiao et al., 2019; Zhang et al., 2019). However, due to the imbalance of the physiological environment under severe conditions, the wound healing process may stop at one of the above stages, resulting in impaired cell function at the wound site and the failure of normal healing. Therefore, an accurate wound management is of great significance to promote wound healing.

One of the promising treatment strategies for promoting wound healing is to provide an artificial matrix as the wound dressing. Simulating the wound healing microenvironment, many wound dressing or skin substitutes have been developed. Specifically, hydrogels have attracted much attention as wound adjuvants because of their high porosity, interconnected macro-porous network, large specific surface area, and appropriate degradation rate, as well as their capability 


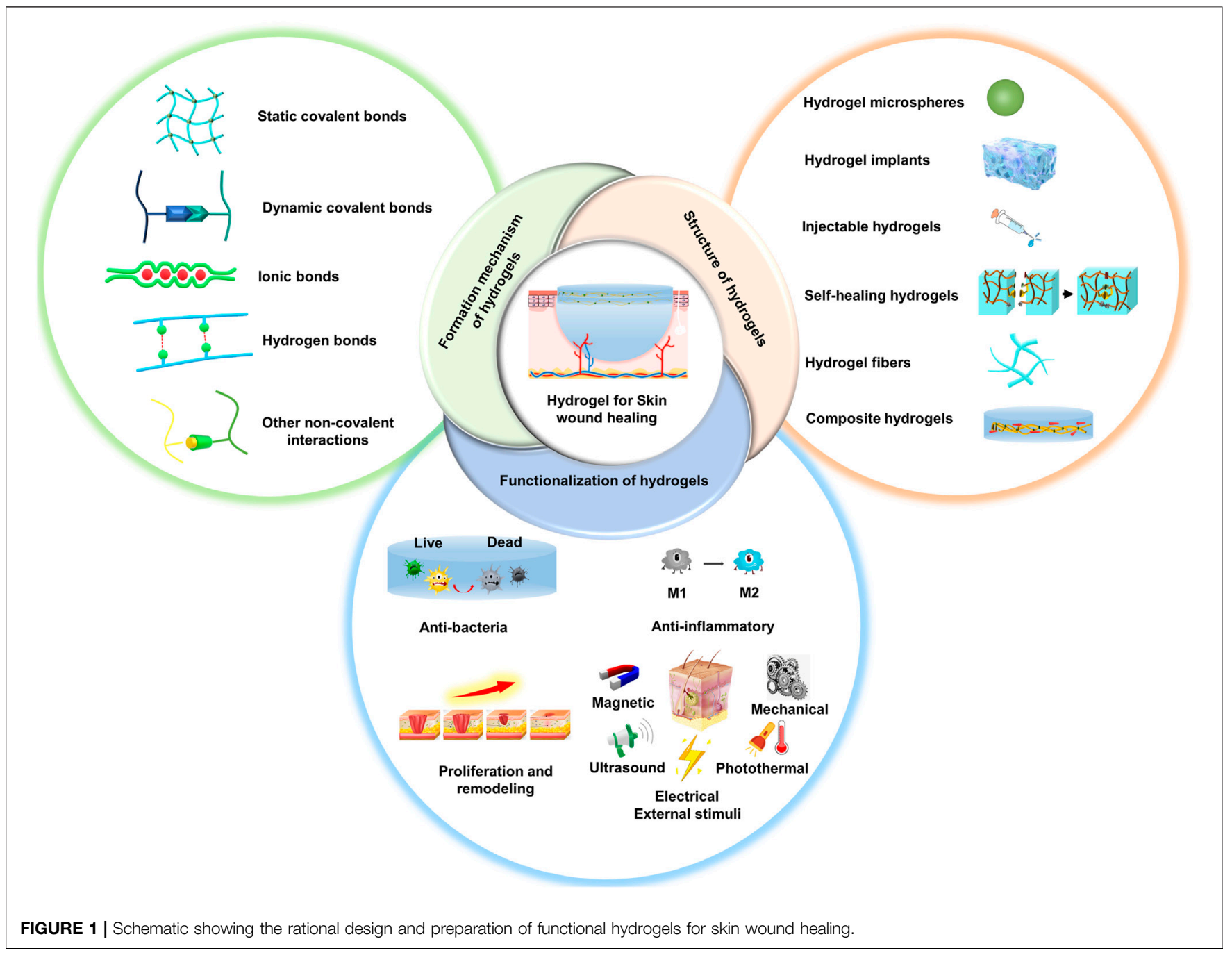

of maintaining moist microenvironment and absorbing tissue exudates (Wang Z. et al., 2019; Asadi et al., 2021). In addition, functional hydrogels can be obtained through rational design and preparation. Among them, injectable in-situ moldable hydrogels are gaining attention, which can be directly applied to irregular wounds (Xuan et al., 2021). A plain hydrogel is often not effective enough in repairing skin wounds by only serving as a covering material. Therefore, it is essential to integrate the hydrogel matrix with typical types of drugs, bioactive factors, cells, and/or specific genes to promote wound repair and accelerate skin regeneration.

The overview of this review is shown in Figure 1. We firstly introduce the design and construction of various types of hydrogels based on their bonding chemistry during crosslinking. Then, we summarize the recent research progress on the functionalization of bioactive hydrogel dressings for skin wound healing (Table 1). Finally, we provide suggestions and perspectives on future directions and improvement strategies for hydrogel wound dressings. We hope that this literature will provide ideas and references for research in the field of skin wound repair.

\section{FORMATION MECHANISM OF HYDROGELS}

\section{Static Covalent Bonds}

Static covalent bonds of hydrogels are formed by chemical reaction or static cross-linking of complementary functional groups. Static covalent bonds are usually stable and robust, but cannot be recovered once broken. Though the self-healing ability of static covalent bonds is relatively weak, on the other hand, it can significantly improve the mechanical properties of hydrogels. For example, a double network hydrogel was prepared by oxidized methacrylic acid sodium alginate and collagenpolypeptide-functionalized carboxymethyl chitosan, which were based on the dynamic covalent Schiff's base bond and UV irradiation to form a static covalent bond (He et al., 2021).

\section{Dynamic Covalent Bonds}

Dynamic covalent bonds are usually reversible covalent bonds formed by dynamic crosslinking, including disulfide, imine, acyl hydrazone, phenylboronate ester, etc. (Yang et al., 2019). 
TABLE 1 | Functional hydrogels for skin wound healing.

\begin{tabular}{|c|c|c|c|c|c|}
\hline Hydrogels & $\begin{array}{l}\text { Bond chemistry } \\
\text { of hydrogels }\end{array}$ & $\begin{array}{l}\text { Structure of } \\
\text { hydrogels }\end{array}$ & $\begin{array}{c}\text { Functionalization of } \\
\text { hydrogels }\end{array}$ & Animal models & References \\
\hline Gelatin/poly (vinyl alcohol) hydrogels & $\begin{array}{l}\text { Dynamic phenylboronic } \\
\text { acid-diol-ester bonds }\end{array}$ & $\begin{array}{l}\text { Injectable } \\
\text { hydrogel }\end{array}$ & $\begin{array}{l}\text { Vancomycin-conjugated silver } \\
\text { nanoclusters, pH-sensitive micelles } \\
\text { loaded with Nimesulide }\end{array}$ & Diabetic rat model & $\begin{array}{l}\text { Wang et al. } \\
\text { (2021b) }\end{array}$ \\
\hline Heparin-poloxamer hydrogels & Amido bond & Patch & Different growth factor (a-FGF and b-FGF) & $\begin{array}{l}\text { Rat full-thickness } \\
\text { skin defect model }\end{array}$ & $\begin{array}{l}\text { Wu et al. } \\
(2016)\end{array}$ \\
\hline Bacterial cellulose/MXene hydrogels & $\begin{array}{l}\text { Hydrogen bond, chemical } \\
\text { covalent cross-linking bond, } \\
\text { chain self-entanglement }\end{array}$ & Patch & $\mathrm{Ti}_{3} \mathrm{C}_{2} \mathrm{TX}-\mathrm{MX}$ Xene & $\begin{array}{l}\text { Rat full-thickness } \\
\text { skin defect model }\end{array}$ & $\begin{array}{l}\text { Mao et al. } \\
(2020)\end{array}$ \\
\hline Calcium peroxide-GelMA hydrogels & $\begin{array}{l}\text { Carbon-carbon covalent } \\
\text { bonds }\end{array}$ & $\begin{array}{l}\text { 3D printed } \\
\text { patch }\end{array}$ & Calcium peroxide & - & $\begin{array}{l}\text { Erdem et al. } \\
(2020)\end{array}$ \\
\hline $\begin{array}{l}\text { Bilayered thiolated alginate/ } \\
\text { polyethylene glycol diacrylate } \\
\text { hydrogels }\end{array}$ & $\begin{array}{l}\text { Disulfide bond, Carbon- } \\
\text { carbon covalent bonds }\end{array}$ & $\begin{array}{l}\text { Bilayered } \\
\text { patch }\end{array}$ & $\begin{array}{l}\text { The small extracellular vesicles (sEVs) } \\
\text { secreted by bone marrow derived } \\
\text { mesenchymal stem cells, and the sEVs } \\
\text { secreted by miR-29b-3p-enriched bone } \\
\text { marrow derived mesenchymal stem cells }\end{array}$ & $\begin{array}{l}\text { Full-thickness skin } \\
\text { defect model of rats } \\
\text { and rabbit ears }\end{array}$ & $\begin{array}{l}\text { Shen et al. } \\
(2021)\end{array}$ \\
\hline $\begin{array}{l}\text { VEGF-decorated t-ZnO-laden } \\
\text { hydrogels }\end{array}$ & $\begin{array}{l}\text { Carbon-carbon covalent } \\
\text { bonds }\end{array}$ & $\begin{array}{l}\text { 3D printed } \\
\text { patch }\end{array}$ & Tetrapodal zinc oxide, VEGF & $\begin{array}{l}\text { Full-thickness skin } \\
\text { defect model }\end{array}$ & $\begin{array}{l}\text { Siebert et al. } \\
(2021)\end{array}$ \\
\hline $\begin{array}{l}\text { Poly (lactic-co-glycolic acid) } \\
\text { microcapsules hydrogels }\end{array}$ & Imine crosslinking & $\begin{array}{l}\text { Injectable } \\
\text { hydrogel }\end{array}$ & TGF- $\beta$ inhibitor & $\begin{array}{l}\text { Rabbit ear and } \\
\text { porcine skin } \\
\text { wounding model }\end{array}$ & $\begin{array}{l}\text { Zhang et al. } \\
\text { (2021a) }\end{array}$ \\
\hline Bio-multifunctional hydrogels & $\begin{array}{l}\text { MgO-catechol, Schiff's base } \\
\text { bond }\end{array}$ & $\begin{array}{l}\text { Injectable } \\
\text { hydrogel }\end{array}$ & $\mathrm{MgO}$ & $\begin{array}{l}\text { Full-thickness } \\
\text { cutaneous defect } \\
\text { and burn model }\end{array}$ & $\begin{array}{l}\text { Tang et al. } \\
(2021)\end{array}$ \\
\hline $\begin{array}{l}\text { Multifunctional double colorimetry- } \\
\text { integrated polyacrylamide- } \\
\text { quaternary ammonium chitosan- } \\
\text { carbon quantum dots-phenol red } \\
\text { hydrogels }\end{array}$ & $\begin{array}{l}\text { Carbon-carbon covalent } \\
\text { bonds, physical } \\
\text { entanglement }\end{array}$ & Patch & Carbon quantum dots, phenol red & $\begin{array}{l}\text { Rat skin defect } \\
\text { model }\end{array}$ & $\begin{array}{l}\text { Zheng et al. } \\
(2021)\end{array}$ \\
\hline $\begin{array}{l}\text { The peptide modified nanofibers } \\
\text { reinforced hydrogels }\end{array}$ & Schiff's base bond & $\begin{array}{l}\text { Composite } \\
\text { hydrogel }\end{array}$ & Antimicrobial peptide (RRRFRADA) & $\begin{array}{l}\text { Murine diabetic } \\
\text { wound healing } \\
\text { model }\end{array}$ & $\begin{array}{l}\text { Qiu et al. } \\
(2021)\end{array}$ \\
\hline $\begin{array}{l}\text { Sodium alginate-chitosan } \\
\text { oligosaccharide-zinc oxide hydrogels }\end{array}$ & Schiff's base bond & Patch & Zinc oxide nanoparticles & $\begin{array}{l}\text { Second-degree } \\
\text { scald wounds } \\
\text { model }\end{array}$ & $\begin{array}{l}\text { Zhang et al. } \\
\text { (2021b) }\end{array}$ \\
\hline Catechol/s-polylysine hydrogels & Schiff's base bond & Patch & Catechol, $\varepsilon$-polylysine & $\begin{array}{l}\text { Burn Wound } \\
\text { Infection Model }\end{array}$ & $\begin{array}{l}\text { Xu et al. } \\
(2019 b)\end{array}$ \\
\hline Polypeptide-based FHE hydrogels & Schiff's base bond & $\begin{array}{l}\text { Injectable and } \\
\text { self-healing }\end{array}$ & $\begin{array}{l}\text { stimuli-responsive adipose-derived } \\
\text { mesenchymal stem cells exosomes }\end{array}$ & Diabetic rat model & $\begin{array}{l}\text { Wang et al. } \\
\text { (2019a) }\end{array}$ \\
\hline Metallohydrogels & Coordination self-assembly & Patch & Amino acid, $\mathrm{Ag}^{+}$ & $\begin{array}{l}\text { Bacterial infection } \\
\text { rat model }\end{array}$ & $\begin{array}{l}\text { Song et al. } \\
(2020)\end{array}$ \\
\hline $\begin{array}{l}\text { Hydrogel/polycaprolactone core/ } \\
\text { shell fiber scaffolds }\end{array}$ & Ionic bond & $\begin{array}{l}\text { 3D printed } \\
\text { patch }\end{array}$ & Polydopamine, doxorubicin & $\begin{array}{l}\text { Rat full-thickness } \\
\text { skin defect model }\end{array}$ & $\begin{array}{l}\text { Liu et al. } \\
(2021)\end{array}$ \\
\hline Gelatin-Tannic acid hydrogels & Hydrogen Bond & Patch & Tannic acid, allantion & $\begin{array}{l}\text { Rat full-thickness } \\
\text { skin defect model }\end{array}$ & $\begin{array}{l}\text { Ahmadian } \\
\text { et al. (2021) }\end{array}$ \\
\hline $\begin{array}{l}\text { Epigallocatechin-3-gallate-3- } \\
\text { acrylamido phenylboronic acid } \\
\text { complex-based polyacrylamide } \\
\text { hydrogels }\end{array}$ & $\begin{array}{l}\text { Boronate ester bond, } \\
\text { phenylboronate ester }\end{array}$ & Patch & $\begin{array}{l}\text { Epigallocatechin-3-gallate, 3-acrylamido } \\
\text { phenylboronic acid }\end{array}$ & $\begin{array}{l}\text { The diabetic rat } \\
\text { model }\end{array}$ & $\begin{array}{l}\text { Zhao et al. } \\
\text { (2021b) }\end{array}$ \\
\hline Injectable multifunctional hydrogels & Schiff's base bond & $\begin{array}{l}\text { Injectable } \\
\text { hydrogel }\end{array}$ & $\begin{array}{l}\varepsilon \text {-polylysine-coated } \mathrm{MnO}_{2} \text { nanosheets, } \\
\text { insulin }\end{array}$ & $\begin{array}{l}\text { The diabetic rat } \\
\text { model }\end{array}$ & $\begin{array}{l}\text { Wang et al. } \\
(2020)\end{array}$ \\
\hline $\begin{array}{l}\text { Polydopamine-modified graphene } \\
\text { oxide hydrogels }\end{array}$ & Schiff's base bond & Patch & Graphene oxide, $\varepsilon$-polylysine & $\begin{array}{l}\text { The diabetic rat } \\
\text { model }\end{array}$ & Tu et al. (2021) \\
\hline Sprayable hydrogels & $\begin{array}{l}\text { Carbon-carbon covalent } \\
\text { bonds }\end{array}$ & sprayable & $\begin{array}{l}\text { Cerium oxide nanoparticles, antimicrobial } \\
\text { peptide }\end{array}$ & Infected rat model & $\begin{array}{l}\text { Cheng et al. } \\
(2021)\end{array}$ \\
\hline $\begin{array}{l}\text { Dual-dynamic-bond cross-linked } \\
\text { antibacterial adhesive hydrogels }\end{array}$ & $\begin{array}{l}\text { pH-sensitive coordinate } \\
\text { bond, Schiff's base bond }\end{array}$ & Patch & Protocatechualdehyde, ferric iron & $\begin{array}{l}\text { Rat skin incision } \\
\text { model }\end{array}$ & $\begin{array}{l}\text { Liang et al. } \\
\text { (2021) }\end{array}$ \\
\hline Polyvinyl alcohol-iodine hydrogels & Hydrogen bond & Patch & lodine & $\begin{array}{l}\text { Rat skin incision } \\
\text { model }\end{array}$ & $\begin{array}{l}\text { Miao et al. } \\
(2021)\end{array}$ \\
\hline Cellulose-based adhesive hydrogels & $\begin{array}{l}\text { Covalent bond, hydrogen } \\
\text { bond, cation- } \pi, \pi-\pi \\
\text { stacking, electrostatic } \\
\text { interaction }\end{array}$ & Patch & - & $\begin{array}{l}\text { Rat full-thickness } \\
\text { skin defect model }\end{array}$ & Lu et al. (2021) \\
\hline
\end{tabular}


Compared with static covalent bonds, dynamic covalent bonds can be reversibly broken and reorganized under a certain external stimulus, such as $\mathrm{pH}$, light, and heat (Chakma and Konkolewicz, 2019; Huang et al., 2020). Therefore, hydrogels with good shape recovery ability and excellent self-healing ability can be prepared by introducing multiple reversible bonds as cross-linking agents. For example, the catechol group in epigallocatechin-3-gallate can form two reversible borate ester bonds with phenylboronic acid, which can be used as a dynamic cross-linking agent to form hydrogel with acrylamide (Zhao X. et al., 2021). This dynamic reversible property endows the hydrogel excellent self-healing properties. Tang et al. (2021) used catechol-modified chitosan and oxidized dextran as the main chain segments of the hydrogels to form dynamic covalent bonds via the Schiff s base reaction, while $\mathrm{MgO}$ and catechol-modified chitosan were chelated as another gel agent to form a double chemical bond hydrogel.

\section{lonic Bonds}

Electrostatic interactions can form ionic bonds, especially between metal ions and nonmetal ions. The formation of ionic bonds can enhance the properties of hydrogels to a certain extent, and different ions can also impart specific characteristics to hydrogels. For instance, magnesium ions bonded cross-linked hydrogels can effectively improve the attachment and enhance the bioactivity of primary osteoblasts in vitro (Yin et al., 2015). Hydrogels based on alginate and chondroitin sulfate are crosslinked by calcium ionic bonds (Fajardo et al., 2012). Under acidic conditions, the functional groups in both alginate and chondroitin sulfate are in neutral form, making the hydrogel network more hydrophobic and thus giving it a $\mathrm{pH}$-dependent water absorption ability. The presence of iron ions can increase the strength of ionic bonds. For example, the carboxyl group in the copolymer of acrylamide and acrylic acid (PAMAAc) strongly interacts with iron through coordination interactions and then generates agar/PAMAAC-Fe ${ }^{3+}$ double network hydrogel (Chen et al., 2016). This highly coordinated interaction dramatically improves the self-healing ability and good fatigue resistance of the hydrogel.

\section{Hydrogen Bonds}

Hydrogen bonding is the intermolecular force between hydrogen atoms and another atom with high electronegativity. Hydrogen bond complexes can be formed by the dense arrangement of hydrogen bonds between polymers. For example, the hydroxyl group of tannic acid acts as the hydrogen donor, and the carboxyl and amino groups of gelatin act as the hydrogen acceptor, forming abundant hydrogen bonds and generating hydrogels rapidly (Ahmadian et al., 2021). Although hydrogen bonds are unstable in an aqueous environment, they are stable under hydrophobic conditions. Hydrogels formed from methacrylic acid and methacrylamide can be cross-linked by hydrogen bonds (Wang Y. J. et al., 2019). Methyl groups are hydrophobic groups that cover hydrogen bonds and stabilize the hydrogel from attack by water molecules. Moreover, the dense and robust hydrogen bonding network gives the hydrogel super stiffness.

\section{Other Non-covalent Interactions}

Other non-covalent bonds also contribute to the formation of hydrogels with a 3D network structure, including hydrophobic interaction (Liu X. et al., 2020), dipole-dipole interaction (Jia et al., 2017), $\pi-\pi$ interaction (Li et al., 2010), electrostatic interaction (Zhang and Khademhosseini, 2017), and host-guest interaction (Sinawang et al., 2020), etc. The non-covalent bond is relatively weak, so multiple types of non-covalent bonds are often used at the same time to form a hydrogel. In addition, noncovalent bond can be applied as a complement to covalent bonds to form hydrogels. For example, an injectable micellar hydrogel was developed by combining Schiffs base dynamic covalent bonds, hydrogen bonding, and $\pi-\pi$ stacking interactions (Yang et al., 2020).

\section{STRUCTURE OF HYDROGELS FOR WOUND HEALING}

\section{Hydrogel Microspheres}

Compared to the traditional bulk hydrogels, hydrogel microspheres are smaller in size and can reach the nanoscale. Hydrogel microspheres can be used to deliver drugs, bioactive factors, and stem cells for tissue repair (Zhao Z. et al., 2021). The commonly used preparation methods of hydrogel microspheres are batch emulsion, microfluidic, lithography, electro jetting, and mechanical crushing (Daly et al., 2020). For example, Griffin et al. (2015) prepared polyethylene glycol-based hydrogel microspheres using a microfluidic emulsion.

\section{Hydrogel Implants}

Hydrogel patches are the most common form of wound dressings. In addition to the use of molds to prepare wound dressing with regular shapes, $3 \mathrm{D}$ printing technology offers a new method for patch preparation. According to the shape of the wound, 3D printing can be used to prepare individualized patches conforming to the shape of the wound. Alizadehgiashi et al. (2021) used cellulose nanocrystals and methyl acrylamidechitosan as printing inks to prepare hydrogel patches with homogeneous composition and mesh structure by $3 \mathrm{D}$ printing for active substance delivery, which is not possible with conventional patches for their incompetent in reaching the deeper layers of the skin. The bulged microstructure on the surface of the patch can penetrate well into the deep part of the damaged skin, realizing the profound delivery of bioactive factors to promote skin repair. Sun et al. (2021) prepared MXeneintegrated microneedle array patches loaded with adenosine to achieve a controlled release under near-infrared (NIR) stimulation.

\section{Injectable Hydrogels}

For irregular wounds, it is difficult for the traditional hydrogel patches to completely and perfectly cover and fit the shape and size of the wound (Gao et al., 2020). Injectable hydrogels offer a solution for the repair of a wound with irregular shapes. The fabrication of injectable hydrogels can be realized by regulating the bond chemistry of hydrogels. Dynamic covalent bonds, ionic 
bonds, hydrogen bonds, and other non-covalent bonds can provide ideas for the preparation of injectable hydrogels. For example, injectable hydrogels were fabricated through a Schiffs base reaction between $\varepsilon$-polylysine-coated $\mathrm{MnO}_{2}$ nanosheets and insulin-loaded self-assembled aldehyde Pluronic F127 micelles (Wang et al., 2020).

\section{Self-Healing Hydrogels}

Due to the low mechanical strength of hydrogel, it is easily damaged during application (Xuan et al., 2021). The development of self-healing ability is crucial for hydrogel patches. Similar to the preparation of injectable hydrogels, self-healing hydrogels can also be realized by reversible dynamic covalent bonds or non-covalent bonds. For instance, a self-healing hydrogel dressing was obtained through the formation of boronate ester (Zhao X. et al., 2021). When the two surfaces of the separated hydrogel contacted to each other, the rearrangement of the boronate ester bond could promote the self-healing of the separated hydrogel. Takashima et al. (2012) reported a self-healing hydrogel based on supramolecular hostguest interaction, which was prepared by copolymerization of acrylamide with the complex of $\beta$-cyclodextrin (host) and adamantane (guest) monomer. After being damaged, the hydrogel was self-healing through the host-guest interaction between $\beta$-cyclodextrin and adamantane. At room temperature, the mechanical properties of the self-healing hydrogel could be fully restored after contact at the cutting site for $24 \mathrm{~h}$, showing excellent self-healing properties.

\section{Hydrogel Fibers}

Compared with traditional hydrogels, hydrogel fibers have a $3 \mathrm{D}$ network structure with a higher specific surface area, which can simulate the structure and characteristics of the ECM and provide more sites for cell adhesion, migration, and proliferation (Li et al., 2021). The standard preparation methods of hydrogel fibers include electrospinning (Liu W. et al., 2020), 3D printing (Kong et al., 2020), microfluidic spinning (Cai et al., 2019), and dynamic polymer spinning (Chen et al., 2020). The most commonly used method is to prepare nanofibers by electrospinning and then cross-link the obtained fibrous membrane to improve its mechanical properties. Chen et al. (2019) successfully prepared gelatin methacryloyl (GelMA) fibers by electrospinning. They soaked the fibrous membrane in the solution containing initiator crosslinking to fabricate hydrogel fibers. Hydrogel fibers can be further functionalized by surface modifications to endow them with special functions. For example, Liu et al. (2021) used 3D printing technology to prepare core-shell hydrogel/Polycaprolactone fibers and grafted a layer of dopamine on the outermost layer to endow it with the ability of NIRtriggered drug release.

\section{Composite Hydrogels}

Although hydrogels can absorb tissue exudates and maintain water balance at the wound site, most hydrogels have poor mechanical properties, limiting their biomedical applications (Teixeira et al., 2021). Qiu et al. (2021) incorporated the peptide modified fiber composite into the hydrogel, and the stability and mechanical strength of the hydrogel was greatly improved. In addition to poor mechanical stability, a plain hydrogel scaffold cannot mimic the complexity of the natural ECM, making the development of novel composite hydrogels critical. For example, gelatin nanofibers were combined with a photo-crosslinking composite hydrogelloaded with epidermal growth factor (EGF) to prepare a bionic bilayer composite hydrogel scaffold (Zandi et al., 2021). In the scaffold, the nanofibers and the EGF-loaded composite hydrogel acted as the dermal and the epidermal layer, respectively.

\section{FUNCTIONALIZATION OF HYDROGELS FOR WOUND HEALING}

\section{Anti-Bacteria and Anti-inflammatory}

When skin injuries occur, microorganisms can easily invade and cause severe wound infections, thus preventing wound healing. Some hydrogel materials have inherent antibacterial properties, such as chitosan (Chi et al., 2020) and modified chitosan (Lu et al., 2020). However, these materials alone are less effective as antimicrobial agents, and therefore the addition of antimicrobial active ingredients is required to achieve an excellent antimicrobial efficacy. The most common solution is to load antimicrobial agents, antibiotics, and/or metal nanomaterials into the hydrogel to treat the infection at the wound site. Wang et al. (2021b) reported an antibacterial hydrogel prepared by coupling vancomycin with silver nanoparticles. $\mathrm{ZnO}$ nanoparticles were also loaded in a hydrogel to endow it with the antibacterial ability (Zhang $M$. et al., 2021). However, the abuse of antimicrobial agents, antibiotics, and metal nanomaterials may lead to drug resistance, making the drugs cytotoxic and limiting their potential applications (Song et al., 2020). In addition to finding new antimicrobial drugs as an alternative, many researchers have chosen incorporating antibacterial peptides, such as Epsilon-Poly-L-lysine antimicrobial peptides, in the hydrogel dressings or microneedles to achieve deep bactericidal effects (Wang C. et al., 2019; Xu M. et al., 2019). Brushing cationic polyelectrolyte poly (dially ldimethyl ammonium chloride) onto bacterial cellulose via surfaceinitiated atom transfer radical polymerization could impart a sustained antimicrobial activity to the resultant hydrogels (Yang Z. et al., 2021). Additionally, hydrogels loaded with cationic carbon dots also showed an antimicrobial function (Cui et al., 2021). The prepared cationic carbon dots had an ultra-high positive charge and a small particle size, which could rapidly bind to bacteria and disrupt their surface charge, leading to the apoptosis of bacteria. To prevent the drug resistance of bacteria, incorporating stimuli-responsive substances into hydrogels and combining them with exogenous physical stimuli can achieve effective antibacterial properties. For instance, a catechol-Fe cross-linked matrix with good photothermal conversion ability was combined with quaternized chitosan, and the resultant hydrogel showed good antibacterial properties under NIR irradiation (Liang et al., 2021). 
The wound healing process is also severely affected by the failure of macrophage response, during which persistently high levels of pro-inflammatory chemokines and large amounts of ROS are presented at the wound site (Kharaziha et al., 2021). The main idea of preparing anti-inflammatory hydrogels is to give them the ability to promote macrophage polarization, eliminate ROS, reduce pro-inflammatory chemokines, and improve inflammatory inhibitory factors. The most common solution is to add anti-inflammatory drugs to the hydrogels. For example, nanomicelles loaded with $\mathrm{pH}$-responsive nimesulide-loaded antiinflammatory drugs can promote the transformation of macrophages from M1-type to M2-type, realizing antiinflammatory function (Wangetal., 2021). In addition to the delivery of anti-inflammatory drugs, loading stem cells and/or genes in hydrogels is another feasible strategy to promote the healing of chronic inflammatory wounds (da Silva et al., 2017). For example, an adhesion GelMA hydrogel containing hyaluronic acid nanoparticles-encapsulated with miR-223 5P mimics was used for chronic wound healing to control the polarization of tissue macrophages (Saleh et al., 2019). Some specific types of ions or elements can regulate the inflammation response. In one study, selenium nanoparticles were loaded into bacterial cellulose/ gelatin hydrogel, which could significantly reduce the expression of TNF- $\alpha$ and IL- 6 , reducing the inflammatory effect during wound healing and promoting wound healing (Mao et al., 2021). Tu et al. (2021) grafted dopamine onto graphene oxide and then loaded the composite into a polydopamine-modified graphene oxide hydrogel. As the catechol on dopamine turned into quinone to trap free radicals, graphene oxide promoted the macrophage polarization, thus conferring the hydrogel with capabilities of anti-inflammatory and capturing ROS. Low levels of reactive oxygen species can promote wound healing, while excessive ROS can hinder wound healing (Xu et al., 2020). Especially in chronic wounds, a sustained inflammation can lead to a high level of ROS, thereby preventing the transition to the next regeneration stage. Therefore, it is particularly important to maintain the balance of ROS level at the wound. Delivering drugs that can scavenge ROS is the most common strategy. For example, thioketone-modified chitosan hydrogel loaded with curcumin could remove excessive ROS to promote wound healing (Yang C. et al., 2021).

\section{Tissue Proliferation and Remodeling}

The proliferation and remodeling periods are the most critical periods of skin wound healing, which mainly involve the formation of granulation tissue, re-epithelialization, angiogenesis, and other events. In the stage of re-tissue regeneration, loading growth factors into hydrogel is an effective manner to improve the wound healing rate. Wu et al. (2016) loaded a-FGF and b-FGF into the thermosensitive heparin-Poloxamer hydrogel, significantly promoting the granulation tissue formation, re-epithelialization, and cell proliferation. However, due to the short half-life and poor stability of growth factors, it is imperative to explore new wound healing agents as an alternative for promoting wound healing. Wang et al. (2021a) isolated a short peptide (RL-QN15) from Rana limnocharis skin secretions, which was proved to promote wound healing in mice. This short peptide could activate the signaling pathway and selectively regulate the secretion of cytokines by macrophages, thereby accelerating the formation of granulation tissue and the regeneration of skin wound.

Hypoxia caused by vascular damage can inhibit wound healing. Therefore, it is extremely important to endow hydrogel trauma excipients with a particular ability to transport oxygen and promote angiogenesis. For example, $\mathrm{MnO}_{2}$ nanosheets were loaded into nanoenzyme-reinforced injectable hyaluronic acid hydrogel to provide oxygen to the wound site because the reaction between the high concentrations of reactive oxygen with the $\mathrm{MnO}_{2}$ nanosheets could generate oxygen (Wang et al., 2020). In addition to the above endogenous oxygen generation methods, calcium peroxide and catalase were added to GelMA hydrogel to produce oxygen continuously (Erdem et al., 2020). This method could not only improve the cell survival rate loaded in GelMA hydrogel, but also provide oxygen for the wound to promote wound healing.

Angiogenesis at skin wounds plays a key role in the transportation of oxygen and nutrients. Therefore, loading growth factors or peptides that promote angiogenesis in hydrogels has become a feasible strategy. For example, Siebert et al. (2021) developed a 3D printing hydrogel patch coated with VEGF and modified by tetrapod zinc oxide ( $\mathrm{t}-\mathrm{ZnO}$ ) particles with photoactivity and antibacterial effect. The controlled release of VEGF could be achieved by chemical modification of $\mathrm{t}-\mathrm{ZnO}$ and activation with ultraviolet/visible light. Endothelial growth factor modified t-ZnO hydrogel patch showed lower cytotoxicity and improved angiogenesis with an excellent antibacterial capability. In addition to the direct release of angiogenesis-related exogenous growth factors, it is another viable means with the use of growth factors secreted from mesenchymal stem cells or stem cell exosomes by paracrine effect to promote angiogenesis. Eke et al. (2017) loaded adiposederived mesenchymal stem cells into hydrogel made of a mixture of GelMA and methacrylic acid hyaluronan. The in vivo results showed that the hydrogel loaded with stem cells could increase vascularization by three times relative to the case without stem cells, thereby accelerating angiogenesis in the damaged skin. Although the above strategies can accelerate the angiogenesis in the wound defect, sometimes the angiogenesis can be extremely slow or blocked under the influence of uncertain factors. In vitro pre-vascularization can be a feasible method. For example, Lei et al. (2019) prepared a hierarchical microchannel network using 3D printing technology, which could reasonably simulate the natural vascular network and showed good structural characteristics.

Scar formation often occurs late in wound healing due to excessive deposition and dislocation of ECM, increased cell density, and chronic inflammation (Xu T. et al., 2019). Scar formation often leads to several complications that can seriously endanger the health of patients. Current research shows that transforming growth factor- $\beta$ (TGF- $\beta$ ) signal transduction disorder is closely associated with pathological scar formation (Song et al., 2019). Therefore, TGF- $\beta$ related pathways have been considered as a very promising target for the treatment of abnormal skin scar formation. Yet, TGF- $\beta$ also 
plays a very important role in the process of wound healing, including regulating the proliferation and differentiation of epidermal cells and dermal cells and regulating tissue regeneration (Mokoena et al., 2018). Therefore, rational delivery of TGF- $\beta$ inhibitors at the late stage of wound healing by certain methods becomes a feasible strategy to inhibit scar formation. For example, Zhang J. et al. (2021) loaded TGF- $\beta$ inhibitor-containing biodegradable microcapsules into a lightcured hydrogel. TGF- $\beta$ inhibitor was released from the microcapsules by pulse during the late wound healing, resulting in the acceleration of skin wound healing and the inhibition of collagen deposition in wounds and thereby reducing scar formation during wound healing. In addition to TGF- $\beta$ inhibitors, Shen et al. (2021) designed and prepared a double-layer sodium alginate/polyethylene glycol diacrylate hydrogel for the continuous release of extracellular vesicles at different wound healing stages to achieve a rapid wound healing. In the late stage of wound healing, the small extracellular vesicles secreted by miR-29b-3p-enriched bone marrow-derived mesenchymal stem cells were released from the upper layer of the hydrogel, inhibiting the excessive capillary proliferation and collagen deposition.

Furthermore, external physical stimuli such as mechanical force (Saiding et al., 2020), photothermal (Zhang X. et al., 2021), electrical filed (Korupalli et al., 2021), ultrasound (Lyu et al., 2021), and magnetic field (Shang et al., 2019) at the wound can also accelerate wound healing. Different from the introduction of various drugs or cells into hydrogels to passively promote wound healing, these exogenous signals can directly and actively regulate the behaviors of fibroblasts, keratinocytes, and epithelial cells, modulating the cell behavior to promote wound healing. In one study, the main network of poly ( $N$-isopropyl acrylamide) hydrogels were formed by free radical polymerization of $N$-isopropyl acrylamide, a temperature-sensitive monomer, while the semi-crosslinked network was further formed by introducing poly (methacrylic acid) (Hu et al., 2021). The hydrogel could effectively accelerate wound healing in mouse and pig models by promoting angiogenesis, collagen deposition and reducing inflammation through the strong adhesion to tissue and mechanical contraction of the wound. Photothermal therapy is another interesting strategy for promoting wound skin repair. Gao et al. (2019) reported a photothermal hydrogel film, which could convert light energy into heat energy under sunlight irradiation. Excessive local wound temperature can reduce inflammation and promote epithelialization, angiogenesis, and collagen deposition. Mao et al. (2020) prepared a cellulose/MXene composite hydrogel, which could actively regulate the cell behavior and improve the cell viability under the external electric field stimulation, accelerating the wound healing process. Ultrasonic treatment can also accelerate the speed of chronic wound healing. Lyu et al. (2021) fabricated flexible ultrasonic patches, in which ultrasound could accelerate the wound healing by activating RAC1 in the dermis and epidermis, thus effectively treating chronic wounds. Shi et al. (2020) seeded normal human dermal fibroblasts on an anisotropic magnetic hydrogel, and the cells were oriented to grow under the guidance of the magnetic field, indicating that the anisotropic magnetic hydrogel showed a beneficial effect on the skin tissue regeneration.

\section{CONCLUSIONS AND PERSPECTIVES}

Hydrogels have been widely used as a wound dressing for skin wound repair because they are simple to prepare and easy to be modified and functionalized. Hydrogels can be fabricated from many natural and synthetic polymers, meanwhile, they can be loaded with a variety of bioactive substances such as growth factors, proteins, genes, etc., thus making them more biologically active to facilitate wound healing. As a dynamic process, wound healing involves several stages, and each stage involves the synergistic action of multiple factors and cells to promote tissue regeneration. Therefore, modulating the on-demand release of active substances according to the specific needs at the different phases has become a major challenge for current wound dressings. On-demand release must focus on the whole process of wound healing but not only on a particular phase. For example, Ma et al. (2020) reported a multilayer injectable hydrogel, which can sequentially deliver bioactive molecules to meet the requirements for bioactivity and timeline of each wound healing stage. In addition, hydrogel scaffolds with integrated monitoring and therapeutic functions will be a new direction for the development of hydrogel wound dressings in the future. By remotely monitoring wound healing process, a real-time dynamic intervene in vivo during the treatment process can be adopted, guiding the targeted therapy. For instance, a wound healing dressing with a double-layer structure can monitor the temperature of the wound in real-time, detect bacterial infection, and release antibiotics through in situ UV irradiation to provide an on-demand infection treatment (Pang et al., 2020). Overall, the ultimate goal is to transfer hydrogels from laboratory to industry, from bench to bedside, and finally achieve a true industrialization for the clinical treatment.

\section{AUTHOR CONTRIBUTIONS}

$\mathrm{RH}$ and ZC wrote the draft of the manuscript. XZ, TM, LZ, FR, and JX revised the manuscript. All authors contributed to the article and approved the submitted version.

\section{FUNDING}

This work is supported by the National Natural Science Foundation of China (Grant No. 82002049 and 52073014; to J. X.), Fundamental Research Funds for the Central Universities (buctrc202020), and Peking University People's Hospital Research and Development Fund RDY 2020-07. 


\section{REFERENCES}

Ahmadian, Z., Correia, A., Hasany, M., Figueiredo, P., Dobakhti, F., Eskandari, M. R., et al. (2021). A Hydrogen-Bonded Extracellular Matrix-Mimicking Bactericidal Hydrogel with Radical Scavenging and Hemostatic Function for pH-Responsive Wound Healing Acceleration. Adv. Healthc. Mater. 10, 2001122. doi:10.1002/adhm.202001122

Alizadehgiashi, M., Nemr, C. R., Chekini, M., Pinto Ramos, D., Mittal, N., Ahmed, S. U., et al. (2021). Multifunctional 3D-Printed Wound Dressings. ACS Nano 15, 12375-12387. doi:10.1021/acsnano.1c04499

Asadi, N., Pazoki-Toroudi, H., Del Bakhshayesh, A. R., Akbarzadeh, A., Davaran, S., and Annabi, N. (2021). Multifunctional Hydrogels for Wound Healing: Special Focus on Biomacromolecular Based Hydrogels. Int. J. Biol. Macromolecules 170, 728-750. doi:10.1016/j.ijbiomac.2020.12.202

Cai, J., Ye, D., Wu, Y., Fan, L., and Yu, H. (2019). Injectable Alginate Fibrous Hydrogel with a Three-Dimensional Network Structure Fabricated by Microfluidic Spinning. Composites Commun. 15, 1-5. doi:10.1016/ j.coco.2019.06.004

Chakma, P., and Konkolewicz, D. (2019). Dynamic Covalent Bonds in Polymeric Materials. Angew. Chem. Int. Ed. 58, 9682-9695. doi:10.1002/anie.201813525

Chen, C., Tang, J., Gu, Y., Liu, L., Liu, X., Deng, L., et al. (2019). Bioinspired Hydrogel Electrospun Fibers for Spinal Cord Regeneration. Adv. Funct. Mater. 29, 1806899. doi:10.1002/adfm.201806899

Chen, G., Wang, G., Tan, X., Hou, K., Meng, Q., Zhao, P., et al. (2020). Integrated Dynamic Wet Spinning of Core-Sheath Hydrogel Fibers for Optical-To-Brain/ tissue Communications. Natl. Sci. Rev. 8, nwaa209. doi:10.1093/nsr/nwaa209

Chen, Q., Yan, X., Zhu, L., Chen, H., Jiang, B., Wei, D., et al. (2016). Improvement of Mechanical Strength and Fatigue Resistance of Double Network Hydrogels by Ionic Coordination Interactions. Chem. Mater. 28, 5710-5720. doi:10.1021/ acs.chemmater.6b01920

Chen, S., Lu, J., You, T., and Sun, D. (2021). Metal-organic Frameworks for Improving Wound Healing. Coord. Chem. Rev. 439, 213929. doi:10.1016/ j.ccr.2021.213929

Cheng, H., Shi, Z., Yue, K., Huang, X., Xu, Y., Gao, C., et al. (2021). Sprayable Hydrogel Dressing Accelerates Wound Healing with Combined Reactive Oxygen Species-Scavenging and Antibacterial Abilities. Acta Biomater. 124, 219-232. doi:10.1016/j.actbio.2021.02.002

Chi, J., Zhang, X., Chen, C., Shao, C., Zhao, Y., and Wang, Y. (2020). Antibacterial and Angiogenic Chitosan Microneedle Array Patch for Promoting Wound Healing. Bioactive Mater. 5, 253-259. doi:10.1016/j.bioactmat.2020.02.004

Cui, F., Sun, J., Ji, J., Yang, X., Wei, K., Xu, H., et al. (2021). Carbon Dots-Releasing Hydrogels with Antibacterial Activity, High Biocompatibility, and Fluorescence Performance as Candidate Materials for Wound Healing. J. Hazard. Mater. 406, 124330. doi:10.1016/j.jhazmat.2020.124330

da Silva, L. P., Santos, T. C., Rodrigues, D. B., Pirraco, R. P., Cerqueira, M. T., Reis, R. L., et al. (2017). Stem Cell-Containing Hyaluronic Acid-Based Spongy Hydrogels for Integrated Diabetic Wound Healing. J. Invest. Dermatol. 137, 1541-1551. doi:10.1016/j.jid.2017.02.976

Daly, A. C., Riley, L., Segura, T., and Burdick, J. A. (2020). Hydrogel Microparticles for Biomedical Applications. Nat. Rev. Mater. 5, 20-43. doi:10.1038/s41578019-0148-6

Eke, G., Mangir, N., Hasirci, N., MacNeil, S., and Hasirci, V. (2017). Development of a UV Crosslinked Biodegradable Hydrogel Containing Adipose Derived Stem Cells to Promote Vascularization for Skin Wounds and Tissue Engineering. Biomaterials 129, 188-198. doi:10.1016/ j.biomaterials.2017.03.021

Erdem, A., Darabi, M. A., Nasiri, R., Sangabathuni, S., Ertas, Y. N., Alem, H., et al. (2020). 3D Bioprinting of Oxygenated Cell-Laden Gelatin Methacryloyl Constructs. Adv. Healthc. Mater. 9, 1901794. doi:10.1002/adhm.201901794

Fajardo, A. R., Silva, M. B., Lopes, L. C., Piai, J. F., Rubira, A. F., and Muniz, E. C. (2012). Hydrogel Based on an Alginate-Ca2+/chondroitin Sulfate Matrix as a Potential colon-specific Drug Delivery System. RSC Adv. 2, 11095-11103. doi:10.1039/c2ra20785k

Gao, Y., Du, H., Xie, Z., Li, M., Zhu, J., Xu, J., et al. (2019). Self-adhesive Photothermal Hydrogel Films for Solar-Light Assisted Wound Healing. J. Mater. Chem. B 7, 3644-3651. doi:10.1039/c9tb00481e
Gao, Y., Li, Z., Huang, J., Zhao, M., and Wu, J. (2020). In Situ formation of Injectable Hydrogels for Chronic Wound Healing. J. Mater. Chem. B 8, 8768-8780. doi:10.1039/d0tb01074j

Griffin, D. R., Weaver, W. M., Scumpia, P. O., Di Carlo, D., and Segura, T. (2015). Accelerated Wound Healing by Injectable Microporous Gel Scaffolds Assembled from Annealed Building Blocks. Nat. Mater 14, 737-744. doi:10.1038/nmat4294

He, Y., Li, Y., Sun, Y., Zhao, S., Feng, M., Xu, G., et al. (2021). A Double-Network Polysaccharide-Based Composite Hydrogel for Skin Wound Healing. Carbohydr. Polym. 261, 117870. doi:10.1016/j.carbpol.2021.117870

Hu, J., Wei, T., Zhao, H., Chen, M., Tan, Y., Ji, Z., et al. (2021). Mechanically Active Adhesive and Immune Regulative Dressings for Wound Closure. Matter 4, 2985-3000. doi:10.1016/j.matt.2021.06.044

Huang, S., Kong, X., Xiong, Y., Zhang, X., Chen, H., Jiang, W., et al. (2020). An Overview of Dynamic Covalent Bonds in Polymer Material and Their Applications. Eur. Polym. J. 141, 110094. doi:10.1016/j.eurpolymj.2020.110094

Jia, H., Huang, Z., Fei, Z., Dyson, P. J., Zheng, Z., and Wang, X. (2017). Bilayered Polyurethane/dipole-Dipole and H-Bonding Interaction Reinforced Hydrogels as Thermo-Responsive Soft Manipulators. J. Mater. Chem. B 5, 8193-8199. doi:10.1039/c7tb02028g

Kharaziha, M., Baidya, A., and Annabi, N. (2021). Rational Design of Immunomodulatory Hydrogels for Chronic Wound Healing. Adv. Mater. 33, 2100176. doi:10.1002/adma.202100176

Kong, B., Chen, Y., Liu, R., Liu, X., Liu, C., Shao, Z., et al. (2020). Fiber Reinforced GelMA Hydrogel to Induce the Regeneration of Corneal Stroma. Nat. Commun. 11, 1435. doi:10.1038/s41467-020-14887-9

Korupalli, C., Li, H., Nguyen, N., Mi, F. L., Chang, Y., Lin, Y. J., et al. (2021). Conductive Materials for Healing Wounds: Their Incorporation in Electroactive Wound Dressings, Characterization, and Perspectives. Adv. Healthc. Mater. 10, 2001384. doi:10.1002/adhm.202001384

Lei, D., Yang, Y., Liu, Z., Yang, B., Gong, W., Chen, S., et al. (2019). 3D Printing of Biomimetic Vasculature for Tissue Regeneration. Mater. Horiz. 6, 1197-1206. doi:10.1039/c9mh00174c

Li, F., Zhu, Y., You, B., Zhao, D., Ruan, Q., Zeng, Y., et al. (2010). Smart Hydrogels Co-switched by Hydrogen Bonds and $\pi-\pi$ Stacking for Continuously Regulated Controlled-Release System. Adv. Funct. Mater. 20, 669-676. doi:10.1002/ adfm. 200901245

Li, Y., Wang, J., Wang, Y., and Cui, W. (2021). Advanced Electrospun Hydrogel Fibers for Wound Healing. Composites B: Eng. 223, 109101. doi:10.1016/ j.compositesb.2021.109101

Liang, Y., Li, Z., Huang, Y., Yu, R., and Guo, B. (2021). Dual-dynamic-bond CrossLinked Antibacterial Adhesive Hydrogel Sealants with On-Demand Removability for post-wound-closure and Infected Wound Healing. ACS Nano 15, 7078-7093. doi:10.1021/acsnano.1c00204

Liu, C., Wang, Z., Wei, X., Chen, B., and Luo, Y. (2021). 3D Printed Hydrogel/PCL Core/shell Fiber Scaffolds with NIR-Triggered Drug Release for Cancer Therapy and Wound Healing. Acta Biomater. 131, 314-325. doi:10.1016/ j.actbio.2021.07.011

Liu, W., Bi, W., Sun, Y., Wang, L., Yu, X., Cheng, R., et al. (2020a). Biomimetic Organic-Inorganic Hybrid Hydrogel Electrospinning Periosteum for Accelerating Bone Regeneration. Mater. Sci. Eng. C 110, 110670. doi:10.1016/j.msec.2020.110670

Liu, X., He, X., Yang, B., Lai, L., Chen, N., Hu, J., et al. (2020b). Dual Physically Cross-Linked Hydrogels Incorporating Hydrophobic Interactions with Promising Repairability and Ultrahigh Elongation. Adv. Funct. Mater. 31, 2008187. doi:10.1002/adfm.202008187

Lu, M., Yu, S., Wang, Z., Xin, Q., Sun, T., Chen, X., et al. (2020). Zwitterionic Choline Phosphate Functionalized Chitosan with Antibacterial Property and superior Water Solubility. Eur. Polym. J. 134, 109821. doi:10.1016/ j.eurpolymj.2020.109821

Lu, S., Zhang, X., Tang, Z., Xiao, H., Zhang, M., Liu, K., et al. (2021). Musselinspired Blue-Light-Activated Cellulose-Based Adhesive Hydrogel with Fast Gelation, Rapid Haemostasis and Antibacterial Property for Wound Healing. Chem. Eng. J. 417, 129329. doi:10.1016/j.cej.2021.129329

Lyu, W., Ma, Y., Chen, S., Li, H., Wang, P., Chen, Y., et al. (2021). Flexible Ultrasonic Patch for Accelerating Chronic Wound Healing. Adv. Healthc. Mater. 10, 2100785. doi:10.1002/adhm.202100785 
Ma, Z., Song, W., He, Y., and Li, H. (2020). Multilayer Injectable Hydrogel System Sequentially Delivers Bioactive Substances for Each Wound Healing Stage. ACS Appl. Mater. Inter. 12, 29787-29806. doi:10.1021/acsami.0c06360

Mao, L., Hu, S., Gao, Y., Wang, L., Zhao, W., Fu, L., et al. (2020). Biodegradable and Electroactive Regenerated Bacterial Cellulose/MXene (Ti 3 C 2 T X) Composite Hydrogel as Wound Dressing for Accelerating Skin Wound Healing under Electrical Stimulation. Adv. Healthc. Mater. 9, 2000872. doi:10.1002/ adhm.202000872

Mao, L., Wang, L., Zhang, M., Ullah, M. W., Liu, L., Zhao, W., et al. (2021). In Situ Synthesized Selenium Nanoparticles-Decorated Bacterial Cellulose/Gelatin Hydrogel with Enhanced Antibacterial, Antioxidant, and Anti-Inflammatory Capabilities for Facilitating Skin Wound Healing. Adv. Healthc. Mater. 10, 2100402. doi:10.1002/adhm.202100402

Miao, Z., Sun, Y., Tao, Z., Chen, Y., Ma, Y., Zhu, D., et al. (2021). Thermochromic Polyvinyl Alcohol-Iodine Hydrogels with Safe Threshold Temperature for Infectious Wound Healing. Adv. Healthc. Mater. 10, 2100722. doi:10.1002/ adhm.202100722

Mokoena, D., Dhilip Kumar, S. S., Houreld, N. N., and Abrahamse, H. (2018). Role of Photobiomodulation on the Activation of the Smad Pathway via TGF- $\beta$ in Wound Healing. J. Photochem. Photobiol. B: Biol. 189, 138-144. doi:10.1016/ j.jphotobiol.2018.10.011

Pang, Q., Lou, D., Li, S., Wang, G., Qiao, B., Dong, S., et al. (2020). Smart Flexible Electronics-Integrated Wound Dressing for Real-Time Monitoring and OnDemand Treatment of Infected Wounds. Adv. Sci. 7, 1902673. doi:10.1002/ advs.201902673

Qiu, W., Han, H., Li, M., Li, N., Wang, Q., Qin, X., et al. (2021). Nanofibers Reinforced Injectable Hydrogel with Self-Healing, Antibacterial, and Hemostatic Properties for Chronic Wound Healing. J. Colloid Interf. Sci. 596, 312-323. doi:10.1016/j.jcis.2021.02.107

Saiding, Q., Jin, J., Qin, M., Cai, Z., Lu, M., Wang, F., et al. (2020). Heat-Shrinkable Electrospun Fibrous Tape for Restoring Structure and Function of Loose Soft Tissue. Adv. Funct. Mater. 31, 2007440. doi:10.1002/adfm.202007440

Saleh, B., Dhaliwal, H. K., Portillo-Lara, R., Shirzaei Sani, E., Abdi, R., Amiji, M. M., et al. (2019). Local Immunomodulation Using an Adhesive Hydrogel Loaded with miRNA-Laden Nanoparticles Promotes Wound Healing. Small 15, 1902232. doi:10.1002/smll.201902232

Shang, W., Chen, G., Li, Y., Zhuo, Y., Wang, Y., Fang, Z., et al. (2019). Static Magnetic Field Accelerates Diabetic Wound Healing by Facilitating Resolution of Inflammation. J. Diabetes Res. 2019, 1-11. doi:10.1155/2019/5641271

Shen, Y., Xu, G., Huang, H., Wang, K., Wang, H., Lang, M., et al. (2021). Sequential Release of Small Extracellular Vesicles from Bilayered Thiolated Alginate/ polyethylene Glycol Diacrylate Hydrogels for Scarless Wound Healing. ACS Nano 15, 6352-6368. doi:10.1021/acsnano.0c07714

Shi, Y., Li, Y., and Coradin, T. (2020). Magnetically-oriented Type I CollagenSiO2@Fe3O4 Rods Composite Hydrogels Tuning Skin Cell Growth. Colloids Surf. B: Biointerfaces 185, 110597. doi:10.1016/j.colsurfb.2019.110597

Siebert, L., Luna-Cerón, E., García-Rivera, L. E., Oh, J., Jang, J., Rosas-Gómez, D. A., et al. (2021). Light-Controlled Growth Factors Release on Tetrapodal ZnOIncorporated 3D-Printed Hydrogels for Developing Smart Wound Scaffold. Adv. Funct. Mater. 31, 2007555. doi:10.1002/adfm.202007555

Sinawang, G., Osaki, M., Takashima, Y., Yamaguchi, H., and Harada, A. (2020). Biofunctional Hydrogels Based on Host-Guest Interactions. Polym. J. 52, 839-859. doi:10.1038/s41428-020-0352-7

Song, G., Yang, R., Zhang, Q., Chen, L., Huang, D., Zeng, J., et al. (2019). TGF- $\beta$ Secretion by M2 Macrophages Induces Glial Scar Formation by Activating Astrocytes In Vitro. J. Mol. Neurosci. 69, 324-332. doi:10.1007/s12031-01901361-5

Song, J., Yuan, C., Jiao, T., Xing, R., Yang, M., Adams, D. J., et al. (2020). Multifunctional Antimicrobial Biometallohydrogels Based on Amino Acid Coordinated Self-Assembly. Small 16, 1907309. doi:10.1002/smll.201907309

Sun, L., Fan, L., Bian, F., Chen, G., Wang, Y., and Zhao, Y. (2021). MXeneintegrated Microneedle Patches with Innate Molecule Encapsulation for Wound Healing. Research 2021, 1-9. doi:10.34133/2021/9838490

Takashima, Y., Hatanaka, S., Otsubo, M., Nakahata, M., Kakuta, T., Hashidzume, A., et al. (2012). Expansion-contraction of Photoresponsive Artificial Muscle Regulated by Host-Guest Interactions. Nat. Commun. 3, 1270. doi:10.1038/ ncomms 2280
Tang, X., Wang, X., Sun, Y., Zhao, L., Li, D., Zhang, J., et al. (2021). Magnesium Oxide-Assisted Dual-Cross-Linking Bio-Multifunctional Hydrogels for Wound Repair during Full-Thickness Skin Injuries. Adv. Funct. Mater. 31, 2105718. doi:10.1002/adfm.202105718

Teixeira, M. O., Antunes, J. C., and Felgueiras, H. P. (2021). Recent Advances in Fiber-Hydrogel Composites for Wound Healing and Drug Delivery Systems. Antibiotics 10, 248. doi:10.3390/antibiotics10030248

Tu, Z., Chen, M., Wang, M., Shao, Z., Jiang, X., Wang, K., et al. (2021). Engineering Bioactive M2 Macrophage-Polarized Anti-Inflammatory, Antioxidant, and Antibacterial Scaffolds for Rapid Angiogenesis and Diabetic Wound Repair. Adv. Funct. Mater. 31, 2100924. doi:10.1002/adfm.202100924

Wang, C., Wang, M., Xu, T., Zhang, X., Lin, C., Gao, W., et al. (2019a). Engineering Bioactive Self-Healing Antibacterial Exosomes Hydrogel for Promoting Chronic Diabetic Wound Healing and Complete Skin Regeneration. Theranostics 9, 65-76. doi:10.7150/thno.29766

Wang, S., Zheng, H., Zhou, L., Cheng, F., Liu, Z., Zhang, H., et al. (2020). Nanoenzyme-reinforced Injectable Hydrogel for Healing Diabetic Wounds Infected with Multidrug Resistant Bacteria. Nano Lett. 20, 5149-5158. doi:10.1021/acs.nanolett.0c01371

Wang, Y., Feng, Z., Yang, M., Zeng, L., Qi, B. e., Yin, S., et al. (2021a). Discovery of a Novel Short Peptide with Efficacy in Accelerating the Healing of Skin Wounds. Pharmacol. Res. 163, 105296. doi:10.1016/j.phrs.2020.105296

Wang, Y. J., Zhang, X. N., Song, Y., Zhao, Y., Chen, L., Su, F., et al. (2019b). Ultrastiff and Tough Supramolecular Hydrogels with a Dense and Robust Hydrogen Bond Network. Chem. Mater. 31, 1430-1440. doi:10.1021/ acs.chemmater.8b05262

Wang, Y., Wu, Y., Long, L., Yang, L., Fu, D., Hu, C., et al. (2021b). Inflammationresponsive Drug-Loaded Hydrogels with Sequential Hemostasis, Antibacterial, and Anti-inflammatory Behavior for Chronically Infected Diabetic Wound Treatment ACS Appl. Mater. Inter. 13, 33584-33599. doi:10.1021/acsami.1c09889

Wang, Z., Wang, Y., Peng, X., He, Y., Wei, L., Su, W., et al. (2019c). Photocatalytic Antibacterial Agent Incorporated Double-Network Hydrogel for Wound Healing. Colloids Surf. B: Biointerfaces 180, 237-244. doi:10.1016/ j.colsurfb.2019.04.043

Wu, J., Zhu, J., He, C., Xiao, Z., Ye, J., Li, Y., et al. (2016). Comparative Study of Heparin-Poloxamer Hydrogel Modified bFGF and aFGF for In Vivo Wound Healing Efficiency. ACS Appl. Mater. Inter. 8, 18710-18721. doi:10.1021/ acsami.6b06047

Xiao, M., Gao, L., Chandrasekaran, A. R., Zhao, J., Tang, Q., Qu, Z., et al. (2019). Bio-functional G-Molecular Hydrogels for Accelerated Wound Healing. Mater. Sci. Eng. C 105, 110067. doi:10.1016/j.msec.2019.110067

Xu, M., Khan, A., Wang, T., Song, Q., Han, C., Wang, Q., et al. (2019a). Musselinspired Hydrogel with Potent In Vivo Contact-Active Antimicrobial and Wound Healing Promoting Activities. ACS Appl. Bio Mater. 2, 3329-3340. doi:10.1021/acsabm.9b00353

Xu, T., Yang, R., Ma, X., Chen, W., Liu, S., Liu, X., et al. (2019b). Bionic Poly( $\gamma$ Glutamic Acid) Electrospun Fibrous Scaffolds for Preventing Hypertrophic Scars. Adv. Healthc. Mater. 8, 1900123. doi:10.1002/adhm.201900123

$\mathrm{Xu}, \mathrm{Z}$., Han, S., Gu, Z., and Wu, J. (2020). Advances and Impact of Antioxidant Hydrogel in Chronic Wound Healing. Adv. Healthc. Mater. 9, 1901502. doi:10.1002/adhm.201901502

Xuan, H., Wu, S., Fei, S., Li, B., Yang, Y., and Yuan, H. (2021). Injectable NanofiberPolysaccharide Self-Healing Hydrogels for Wound Healing. Mater. Sci. Eng. C 128, 112264. doi:10.1016/j.msec.2021.112264

Yang, B., Song, J., Jiang, Y., Li, M., Wei, J., Qin, J., et al. (2020). Injectable Adhesive SelfHealing Multicross-Linked Double-Network Hydrogel Facilitates Full-Thickness Skin Wound Healing. ACS Appl. Mater. Inter. 12, 57782-57797. doi:10.1021/ acsami.0c18948

Yang, C., Chen, Y., Huang, H., Fan, S., Yang, C., Wang, L., et al. (2021a). ROSeliminating Carboxymethyl Chitosan Hydrogel to Enhance Burn WoundHealing Efficacy. Front. Pharmacol. 12, 679580. doi:10.3389/fphar.2021.679580

Yang, J., Bai, R., Chen, B., and Suo, Z. (2019). Hydrogel Adhesion: A Supramolecular Synergy of Chemistry, Topology, and Mechanics. Adv. Funct. Mater. 30, 1901693. doi:10.1002/adfm.201901693

Yang, Z., Huang, R., Zheng, B., Guo, W., Li, C., He, W., et al. (2021b). Highly Stretchable, Adhesive, Biocompatible, and Antibacterial Hydrogel Dressings for Wound Healing. Adv. Sci. 8, 2003627. doi:10.1002/advs.202003627 
Yin, M., Xu, F., Ding, H., Tan, F., Song, F., and Wang, J. (2015). Incorporation of Magnesium Ions into Photo-Crosslinked Alginate Hydrogel Enhanced Cell Adhesion Ability. J. Tissue Eng. Regen. Med. 9, 1088-1092. doi:10.1002/ term. 2011

Zandi, N., Dolatyar, B., Lotfi, R., Shallageh, Y., Shokrgozar, M. A., Tamjid, E., et al. (2021). Biomimetic Nanoengineered Scaffold for Enhanced Full-Thickness Cutaneous Wound Healing. Acta Biomater. 124, 191-204. doi:10.1016/j.actbio.2021.01.029

Zhang, J., Zheng, Y., Lee, J., Hua, J., Li, S., Panchamukhi, A., et al. (2021a). A Pulsatile Release Platform Based on Photo-Induced Imine-Crosslinking Hydrogel Promotes Scarless Wound Healing. Nat. Commun. 12, 1670. doi:10.1038/s41467-021-21964-0

Zhang, M., Qiao, X., Han, W., Jiang, T., Liu, F., and Zhao, X. (2021b). Alginatechitosan Oligosaccharide-ZnO Composite Hydrogel for Accelerating Wound Healing. Carbohydr. Polym. 266, 118100. doi:10.1016/j.carbpol.2021.118100

Zhang, S., Ou, Q., Xin, P., Yuan, Q., Wang, Y., and Wu, J. (2019). Polydopamine/ puerarin Nanoparticle-Incorporated Hybrid Hydrogels for Enhanced Wound Healing. Biomater. Sci. 7, 4230-4236. doi:10.1039/c9bm00991d

Zhang, X., Tan, B., Wu, Y., Zhang, M., and Liao, J. (2021c). A Review on Hydrogels with Photothermal Effect in Wound Healing and Bone Tissue Engineering. Polymers 13, 2100. doi:10.3390/polym13132100

Zhang, Y. S., and Khademhosseini, A. (2017). Advances in Engineering Hydrogels. Science 356, 6337. doi:10.1126/science.aaf3627

Zhao, X., Pei, D., Yang, Y., Xu, K., Yu, J., Zhang, Y., et al. (2021a). Green tea Derivative Driven Smart Hydrogels with Desired Functions for Chronic Diabetic Wound Treatment. Adv. Funct. Mater. 31, 2009442. doi:10.1002/adfm.202009442
Zhao, Z., Wang, Z., Li, G., Cai, Z., Wu, J., Wang, L., et al. (2021b). Injectable Microfluidic Hydrogel Microspheres for Cell and Drug Delivery. Adv. Funct. Mater. 31, 2103339. doi:10.1002/adfm.202103339

Zheng, K., Tong, Y., Zhang, S., He, R., Xiao, L., Iqbal, Z., et al. (2021). Flexible Bicolorimetric Polyacrylamide/Chitosan Hydrogels for Smart Real-Time Monitoring and Promotion of Wound Healing. Adv. Funct. Mater. 31, 2102599. doi:10.1002/adfm.202102599

Conflict of Interest: The authors declare that the research was conducted in the absence of any commercial or financial relationships that could be construed as a potential conflict of interest.

Publisher's Note: All claims expressed in this article are solely those of the authors and do not necessarily represent those of their affiliated organizations, or those of the publisher, the editors, and the reviewers. Any product that may be evaluated in this article, or claim that may be made by its manufacturer, is not guaranteed or endorsed by the publisher.

Copyright (c) 2022 Hao, Cui, Zhang, Tian, Zhang, Rao and Xue. This is an openaccess article distributed under the terms of the Creative Commons Attribution License (CC BY). The use, distribution or reproduction in other forums is permitted, provided the original author(s) and the copyright owner(s) are credited and that the original publication in this journal is cited, in accordance with accepted academic practice. No use, distribution or reproduction is permitted which does not comply with these terms. 